\title{
Practical progress in realisation of early diagnosis and treatment of patients with suspected rheumatoid arthritis: results from two matched questionnaires within three years
}

\author{
D Aletaha, G Eberl, V P K Nell, K P Machold, J S Smolen
}

Ann Rheum Dis 2002;61:630-634

Background: Early diagnosis and treatment with disease modifying antirheumatic drugs (DMARDs) have been advocated for patients with rheumatoid arthritis (RA). This survey focuses on the individual definitions and treatment modalities of rheumatologists, and aims at determining the practical realisation of these concepts.

Methods: A questionnaire to be self completed was handed out at the EULAR Symposium 1997. The main issues dealt with were definition, referral time, diagnosis, follow up, and treatment of early RA. Of the 111 participants, who were from all continents and all age groups, $85(77 \%)$ gave their name and address. In 2000, the same questionnaire was sent to these 85 primary respondents. Forty four questionnaires (52\%) were returned, and their results were matched and further evaluated.

Results: The definition of early RA was heterogeneous, but two of three rheumatologists use the term "early" for symptoms shorter than three months. There was a drift towards acceptance of involvement of fewer affected joints. Serological tests obtained for early diagnosis were mostly rheumatoid factor and antinuclear antibodies, usually in combination (approximately $70 \%$ ), while other tests (antikeratin antibodies, antiperinuclear factor, anti-RA33) were used rarely, but increasingly (21-25\% all together). No significant change in the lag time of referral to the specialist of patients with suspected early RA was seen within these three years $<3$ months for $50 \%$, $>6$ months for $20 \%$, while the proportion followed up during the first three months increased. At both times, every second rheumatologist started DMARD treatment only when the 1987 American College of Rheumatology (ACR) criteria were fulfilled. However, in 1997 about 10\% were willing to wait for erosions before starting DMARDs, while none did so in 2000. Methotrexate, sulfasalazine, and antimalarial drugs were the most commonly prescribed DMARDs in early RA, with the first two of these still being in increasing use.

Conclusion: The understanding of "early" rheumatoid arthritis is heterogeneous, but the vast majority of the rheumatologists surveyed regard symptom duration of $<3$ months as early. Rheumatoid factor was the most useful laboratory support in early diagnosis. Because there has been no shortening of referral time of patients with new RA within the past three years, and many rheumatologists start DMARDs only when the ACR criteria are fulfilled, it is concluded that guidelines for early referral, as well as for early (rheumatoid) arthritis, are needed.
O ver many decades disease modifying antirheumatic drugs (DMARDs) have been used reluctantly in rheumatoid arthritis (RA), while at the same time symptomatic treatment with non-steroidal anti-inflammatory drugs (NSAIDs) has been advocated at early stages of the disease, and remission was thought to be quite common. ${ }^{12}$ It has been shown that this "therapeutic pyramid" is insufficient to prevent joint damage $e^{3}$ and the early use of DMARDs has been propagated during the past decade. ${ }^{45}$ In fact, several trials have shown the efficacy of the traditional DMARDs in early arthritis, ${ }^{6-10}$ but "early arthritis" is ill-defined: in some studies a disease duration of up to three years was accepted, ${ }^{67}$ whereas other protocols required a much shorter maximum duration of symptoms. ${ }^{8-10}$

In this study we analysed the results of a survey performed among rheumatologists. Important aspects were to explore what rheumatologists describe as "early" RA, and to determine the average lag time of referral to the specialist for patients with suspected RA and to initiation of DMARD treatment.

\section{METHODS}

A questionnaire to be self completed concerning early RA was designed. The questions focused on definition, referral time of patients, diagnostic approach, follow up of these patients, and treatment of patients with early RA (table 1). The questions were of closed style type, mostly offering categories of different answers. The first questionnaire was handed to participants at the EULAR Symposium in November 1997. One hundred and eleven questionnaires were returned. Of these respondents, 94 (85\%) were rheumatologists, nine $(8 \%)$ rheumatologists in training, six (5\%) non-rheumatological clinicians, and two (2\%) basic scientists. Fifty three $(48 \%)$ were working in Europe, 58 (52\%) in countries outside Europe, and all continents were represented. The respondents' affiliations were universities for 59 (53\%), city hospitals for 43 (39\%), and private practices for nine $(8 \%)$.

Eighty five (77\%) of the primary respondents also gave their name and postal address. In August 2000, these 85 colleagues were sent a follow up questionnaire which was identical to the first one; 44 (52\%) responded. As before, the responders were primarily rheumatologists $(42 / 44(95 \%))$, and their affiliations were similar to those previously $(25(57 \%)$ at universities, 15 $(34 \%)$ at city hospitals, and four $(9 \%)$ in private practices).

Abbreviations: ACR, American College of Rheumatology; AKA antikeratin antibodies; APF, antiperinuclear factor; DMARDs, disease modifying antirheumatic drugs; MTX, methotrexate; RA, rheumatoid arthritis; RF, rheumatoid factor; SSZ, sulfasalazine 


\begin{tabular}{|c|c|c|}
\hline Topic & Item(s) & Possible answers \\
\hline Definition & $\begin{array}{l}\text { What do you regard as early RA? } \\
\text { A. Type of arthritis (at least) } \\
\text { B. Duration of symptoms (one answer) }\end{array}$ & $\begin{array}{l}\text { A. At least: polyarthritis (>5 joints)/oligoarthritis }(2-5 \\
\text { joints)/monarthritis } \\
\text { B. }<6 \text { Weeks/ }<3 \text { months / }<6 \text { months/ }<12 \text { months/other, } \\
\text { please specify }\end{array}$ \\
\hline Referral time & $\begin{array}{l}\text { How long on average does it take from onset of their symptoms } \\
\text { until patients with arthritis are referred to you? (one answer) }\end{array}$ & $<6$ Weeks $/<3$ months $/<6$ months $/<12$ months $/>12$ months \\
\hline Diagnostic approach & $\begin{array}{l}\text { Which serological tests do you use in early diagnosis? (several } \\
\text { answers) }\end{array}$ & $\begin{array}{l}\text { Rheumatoid factor/antinuclear antibodies/antikeratin } \\
\text { antibodies/antiperinuclear factor/anti-RA33 }\end{array}$ \\
\hline Follow up of patients & $\begin{array}{l}\text { How often do you see your patients with early arthritis during } \\
\text { the first } 3 \text { months? (one answer) } \\
\text { How many patients with early arthritis do you see each year? }\end{array}$ & Every 2 weeks/every month/every 3 months/not at all \\
\hline Treatment & $\begin{array}{l}\text { When do you start DMARD treatment in patients with newly } \\
\text { diagnosed RA? (one answer) } \\
\text { In newly diagnosed patients, which DMARDs do you prescribe } \\
\text { most commonly? (maximum of two answers) }\end{array}$ & $\begin{array}{l}\text { When erosions have occurred/when ACR criteria are } \\
\text { fulfilled/when RA is suspected/when NSAIDs have failed }<12 \\
\text { months/ }>6 \text { months/ }>3 \text { months/other, please specify } \\
\text { Azathioprine/chloroquine/hydroxychloroquine/ } \\
\text { chlorambucil/cyclophosphamide/cyclosporin A/ } \\
\text { D-penicillamine/gold compounds oral/gold compounds } \\
\text { parenteral/methotrexate/sulfasalazine/other, please specify }\end{array}$ \\
\hline
\end{tabular}

Data were registered and processed using version 10.0 of the Statistical Package for the Social Sciences. The questionnaires returned in 2000 were matched individually with those from 1997. Also, we present graphically the results of all 111 primary respondents to provide an estimate of potential nonresponder bias.

\section{RESULTS}

\section{Definition of early RA}

Firstly, the participants were asked to define early arthritis by type of arthritis and duration of symptoms (table 1). Whereas in $19979 \%$ regarded monarthritis as a potential manifestation of early RA, in 2000 18\% did so, while the proportion requiring
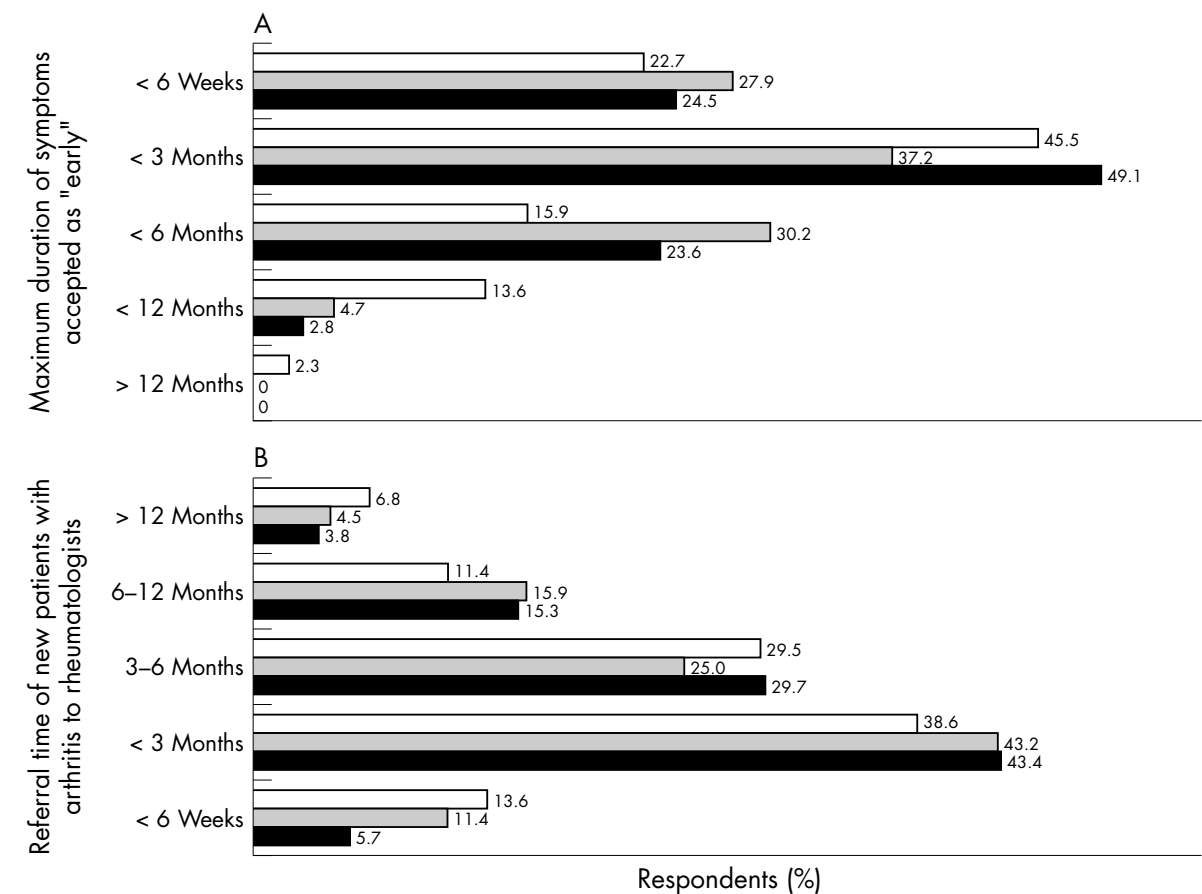

Respondents (\%)

Opinions in the second questionnaire $(2000 ; n=43)$

Opinions in the first questionnaire of those who responded to the second one (1997; $n=43$ )

Opinions of all original respondents to the first questionnaire 1997; $\mathrm{n}=102$ for type, $\mathrm{n}=106$ for duration)

Figure 1 (A) What maximum duration of symptoms do you still regard as early RA? (Only one answer was possible): bars represent the percentage of valid answers. (B) How long on average does it take from onset of their symptoms until patients with arthritis are referred to you? (Only one answer was possible): Bars represent the percentage of valid answers. 
the presence of polyarthritis decreased by $20 \%$ (28\% in 1997 to $23 \%$ in 2000). At both times approximately two of three rheumatologists would use the term "early RA" only if the duration of symptoms was $<3$ months (fig lA).

The numbers of so-defined patients with early arthritis seen each year by the rheumatologists were similar at both times: the median number (and quartiles) of patients with early RA seen each year was $20(10 ; 35)$ in 1997 and $18(10 ; 50)$ in 2000. The median proportion of patients with early RA among all patients with RA seen each year was $11.3 \%(5.8 \% ; 22.1 \%)$ in 1997 and $13.7 \%(6.3 \% ; 20.0 \%)$ in 2000.

\section{Referral time of patients with suspected RA to rheumatologists (fig 1B)}

Early referral of patients with symptoms of arthritis or suspected RA is mandatory for early diagnosis and treatment. During the past three years no significant change took place. Almost 50\% of the respondents indicated that patients with arthritis were referred $>3$ months from onset of disease, while $54.6 \%$ (1997) and $52.2 \%$ (2000) stated a referral time of $<3$ months.

\section{Serological tests in early diagnosis}

Apart from clinical presentation, we asked about the serological tests that were used to support diagnosis of early RA. Traditional tests that have been shown to be useful in diagnosis of RA were offered ${ }^{11}$ : rheumatoid factor (RF), antikeratin antibodies (AKA), antiperinuclear factor (APF), and antiRA33. RF testing was used by all respondents, but only a small proportion used the other serological tests (AKA, APF, anti-RA33) to support a diagnosis of early RA ( $18 \%$ in 1997 , $25 \%$ in 2000 ). Also, antinuclear antibodies were used by $70 \%$ for differential diagnostic purposes.

\section{Follow up of patients with early RA}

Most rheumatologists prefer monthly follow up visits for their patients with early arthritis during the first three months (66\% in 1997, 52\% in 2000). There was a notable shift towards more frequent (two weekly) follow up (16\% in 1997, $26 \%$ in 2000 ), but the proportion of rheumatologists who were seeing their patients less often (once or not at all during the first three months) was similar at both times (18\% v21\%).

\section{Treatment of early RA}

At both times almost every second participant (49\%) would start treatment with DMARDs when American College of Rheumatology (ACR) criteria for RA were fulfilled (fig 2A). Importantly, whereas in 1997 almost 10\% were waiting for evidence of erosions before initiating DMARD treatment, in 2000 none did so. The proportion of respondents who would start DMARDs if suspecting RA even in the absence of four ACR criteria increased by one third (27.9\% to $37.2 \%)$.

DMARD types employed in patients with newly diagnosed RA were mostly methotrexate (MTX), sulfasalazine (SSZ), and antimalarial drugs (fig 2B), with the first two still increasing $(89 \%$ and $64 \%$ in 2000 , which is a relative increase of $8 \%$ and $17 \%$, respectively, during the past three years), and the latter in relatively unchanged proportion. Also, cyclosporin A was occasionally used as the first DMARD, while cyclophosphamide, chlorambucil, and auranofin (oral gold) were not used at all in patients with new RA in 2000 by the participating rheumatologists. The use of parenteral gold compounds decreased by $40 \%$ in the daily practice of the respondents. The participants were asked to select their two favourite DMARDs in this question: those who were using MTX, most commonly also liked to prescribe SSZ and vice versa, while those using antimalarial drugs mostly preferred MTX as alternative option (data not shown).

\section{DISCUSSION}

About $10 \%$ of patients with RA seen by the participating rheumatologists had "early" RA. The interpretation of this proportion is problematic, as we found a considerable heterogeneity in what rheumatologists define as "early". Contrary to a recent report, ${ }^{12}$ the present data suggest that in the opinion of international rheumatologists there is still a considerable lag period of patient referral: about half of the rheumatologists see their patients for the first time beyond the three months margin which most of them regard as the borderline of "early disease". Improved referral is needed..$^{13}$

Support for diagnosis of RA comes from laboratory tests, mainly for RF. A significantly raised RF indicates those with increased susceptibility to developing RA, ${ }^{11-14}$ and thus, is sensitive in the early diagnosis of patients with suspected symptoms of RA. ${ }^{15}$ Newer markers of RA (AKA, APF, anti-RA33) were only used by a small proportion of the respondents, but have been increasingly used in the past three years.

One limitation of analysing questionnaires is bias. In this study three main sources of bias are possible. Firstly, a selection was made by choosing attendants of an international rheumatology meeting. Secondly, respondents to the first questionnaire might not have been a random sample of the attendants at the meeting, but rather participants who were more interested in RA, early RA, or treatment of RA. Bias on these two grounds can be regarded as directed towards the selection of opinion leaders, and thus, a real random sample might have shown an even smaller transposition of early diagnosis and treatment into clinical practice. Finally, the response rate to the second questionnaire in 2000 was $52 \%$, raising the issue of non-response bias. One source of non-response might be the personalisation of the questionnaires, but this seems unlikely as all non-responders in 2000 participated voluntarily in 1997 and had voluntarily given their names. To provide a method to estimate the effect size caused by this type of bias, data on the opinions of the original participants are also presented in the figures. Despite these sources of potential bias, the value of this study lies in the broad representation of the respondents, who were from 35 countries and all continents.

At both the time points 1997 and 2000 the most commonly used DMARDs were MTX, SSZ, and antimalarial drugs. Interestingly, although there were two major differences between the responses for most other questions, the treatment behaviour appeared to have changed: gold salts were used $45 \%$ less frequently in 2000 than in 1997, while the use of SSZ and MTX was still increasing. The use of antimalarial drugs remained relatively stable. It will be interesting to learn of changes of treatment behaviour with the introduction of the newly approved DMARDs.

The most important aspect of this study is the opinion of the practising rheumatologists that RA should be regarded as early only within the first three months from onset of symptoms. This is in line with conclusions from clinical and from observational studies of early RA, ${ }^{16}{ }^{17}$ but has been derived by simple questioning of practising rheumatologists. The congruence of data obtained from prospective studies and results from questionnaires gives this time frame additional validity. Secondly, we found that almost $50 \%$ of rheumatologists await fulfilment of classification criteria of disease (the 1987 ACR criteria) before starting treatment with DMARDs. However, these criteria are not useful in early diagnosis, ${ }^{18}$ but it may be understandable that, given the lack of diagnostic criteria for early RA, for many rheumatologists the initiation of potentially toxic drugs is not justified before a diagnosis is unequivocally established. Therefore, to better define early arthritis a core set and revised recommendations are needed. This demand for definitions is not only an academic need (for example, in clinical trials), but is also important in daily practice, where one major decision is when to start DMARDs. With 

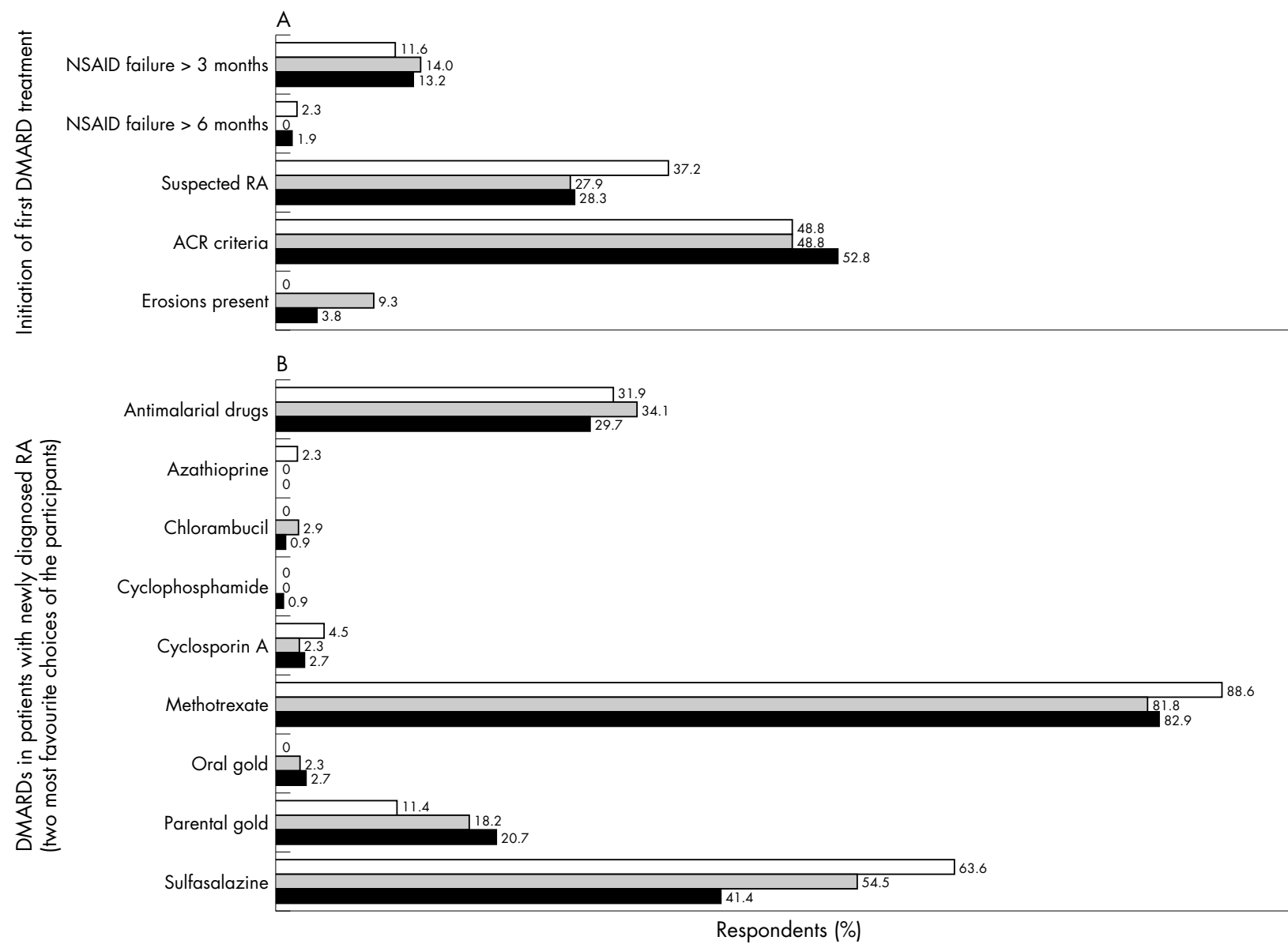

Respondents $(\%)$

$\square$ Opinions in the second questionnaire $(2000 ; n=44)$

$\square$ Opinions in the first questionnaire of those who responded to the second one $(1997 ; n=44)$

Opinions of all original respondents to the first questionnaire (1997; $n=102$ )

Figure 2 (A) When do you start DMARD treatment in patients with newly diagnosed RA? (Only one answer was possible): Bars represent the percentage of valid answers. (B) In newly diagnosed patients, which DMARDs do you prescribe most often? (The two most favourite choices were requested): Bars represent the percentage of valid answers.

such recommendations, the importance of recognising early RA and the success of early treatment will be more apparent.

\section{ACKNOWLEDGEMENT}

We thank all participants of this survey for their time and thoughtful completion of the questionnaires.

\section{Authors' affiliations}

D Aletaha, V P K Nell, K P Machold, J S Smolen, Division of Rheumatology, Department of Internal Medicine III, University of Vienna,

Vienna, Austria

G Eberl, J S Smolen, Second Department of Medicine, Lainz Hospital, Vienna, Austria

G Eberl, J S Smolen, Ludwig Boltzmann Institute for Rheumatology,

Vienna, Austria

Correspondence to: Professor J S Smolen, Division of Rheumatology, Department of Internal Medicine III, University of Vienna, Vienna General Hospital, Waehringer Guertel 18-20, A-1090 Vienna, Austria; smj@2me.khl.magwien.gv.at

Accepted 7 January 2002

\section{REFERENCES}

1 Cathcart ES, O'Sullivan JB. Rheumatoid arthritis in a New England town.

A prevalence study in Sudbury, Massachusetts. N Engl J Med

1970;282:421-4.
2 Short CL, Baver W. The course of rheumatoid arthritis in patients receiving simple medical and orthopedic measures. N Engl J Med 1948;238:142-8

3 Pincus T. Long-term outcomes in rheumatoid arthritis. Br J Rheumato 1995;34(suppl 2):59-73.

4 van de Putte LB, van Gestel AM, van Riel PL. Early treatment of rheumatoid arthritis: rationale, evidence, and implications. Ann Rheum Dis 1998;57:511-12.

5 Wilske KR, Healey LA. Remodeling the pyramid-a concept whose time has come. J Rheumatol 1989;16:565-7.

6 Egsmose C, Lund B, Borg G, Pettersson H, Berg E, Brodin U, et al. Patients with rheumatoid arthritis benefit from early 2nd line therapy: 5 year followup of a prospective double blind placebo controlled study. Rheumatol 1995:22:2208-13

7 Bathon JM, Martin RW, Fleischmann RM, Tesser JR, Schiff MH, Keystone $E C$, et al. A comparison of etanercept and methotrexate in patients with early rheumatoid arthritis. N Engl J Med 2000;343:1586-93.

8 van Jaarsveld $\mathbf{C H}$, Jacobs JW, van der Veen $M$, Blaauw AA, Kruize $A A$, Hofman DM, et al. Aggressive treatment in early rheumatoid arthritis: a randomised controlled trial. On behalf of the Rheumatic Research Foundation Utrecht, The Netherlands. Ann Rheum Dis 2000;59:468-77.

9 Proudman SM, Conaghan PG, Richardson C, Griffiths B, Green M, McGonagle $D$, et al. Treatment of poor-prognosis early rheumatoid arthritis. A randomized study of treatment with methotrexate, cyclosporin A, and intraarticular corticosteroids compared with sulfasalazine alone. Arthritis Rheum 2000;43:1809-19.

10 Dougados M, Combe B, Cantagrel A, Goupille P, Olive P, Schattenkirchner $M$, et al. Combination therapy in early rheumatoid arthritis: a randomised, controlled, double blind 52 week clinical trial of sulphasalazine and methotrexate compared with the single components. Ann Rheum Dis 1999;58:220-5. 
11 Williams DG. Autoimmunity in rheumatoid arthritis. In: Klippel JH Dieppe PA, eds. Rheumatology. St Louis: Mosby, 1994:9.1-14.

12 Irvine S, Munro R, Porter D. Early referral, diagnosis, and treatment of rheumatoid arthritis: evidence for changing medical practice. Ann Rheum Dis 1999:58:510-13

13 Emery P. Visions of the future in arthritis care. Scand J Rheumatol Suppl 1999;109:3-11.

14 Aho K, Palosuo T, Raunio V, Tuomi T. The timing of rheumatoid factor seroconversions. Arthritis Rheum 1987;30:719-20.

15 van der Heijde DM, van Riel PL, van Leeuwen MA, ' $†$ Hof MA, van Rijswijk MH, van de Putte LB. Prognostic factors for radiographic damage and physical disability in early rheumatoid arthritis. A prospective follow-up study of 147 patients. $\mathrm{Br} J$ Rheumatol 1992:31:519-25.

16 Green M, Marzo-Ortega H, McGonagle D, Wakefield R, Proudman S, Conaghan $P$, et al. Persistence of mild, early inflammatory arthritis: the importance of disease duration, rheumatoid factor, and the shared epitope. Arthritis Rheum 1999;42:2184-8.

17 Harrison B. Symmons D. Early inflammatory polyarthritis: results from the Norfolk Arthritis Register with a review of the literature. II. Outcome at three years. Rheumatology (Oxford) 2000;39:939-49.

18 Silman AJ, Symmons DP. Selection of study population in the development of rheumatic disease criteria: comment on the article by the American College of Rheumatology Diagnostic and Therapeutic Criteria Committee. Arthritis Rheum 1995;38:722-3.

\section{Call for peer reviewers}

Clinical Evidence is a regularly updated evidence based journal available world wide both as a paper version and on the internet. Clinical Evidence urgently needs to recruit a number of new contributors. Contributors are health care professionals or epidemiologists with experience in evidence based medicine and the ability to write in a concise and structured way.

Clinical Evidence needs to recruit a number of new peer reviewers. Peer reviewers are health care professionals or epidemiologists with experience in evidence based medicine. As a peer reviewer you would be asked for your views on the clinical relevance, validity and accessibility of specific topics within the journal, and their usefulness to the intended audience (international generalists and health care professionals, possibly with limited statistical knowledge). Topics are usually 2000-3000 words in length and we would ask you to review between 2-5 topics per year. The peer review process takes place throughout the year, and our turnaround time for each review is ideally 10-14 days.

If you are interested in becoming a peer reviewer for Clinical Evidence, please complete the peer review questionnaire at www.clinicalevidence.com or contact Polly Brown (pbrown@bmigroup.com). 